\title{
OXYGEN CROSSOVER IN SOLID-SOLID HEAT EXCHANGERS FOR SOLAR WATER AND CARBON DIOXIDE SPLITTING: A THERMODYNAMIC ANALYSIS
}

\author{
Philipp Holzemer-Zerhusen ${ }^{\mathrm{a}, \mathrm{b}, 1}$, Stefan Brendelberger ${ }^{\mathrm{a}}$, Martin Roeb ${ }^{\mathrm{a}}$, Christian Sattler $^{\mathrm{a}, \mathrm{b}}$ \\ ${ }^{a}$ German Aerospace Center (DLR), Institute of Solar Research, Cologne, Germany \\ ${ }^{\mathrm{b}} \mathrm{TU}$ Dresden, Faculty of Mechanical Science and Engineering, Institute of Power Engineering, \\ Dresden, Germany
}

\begin{abstract}
In solar thermochemical redox cycles for $\mathrm{H}_{2} \mathrm{O} / \mathrm{CO}_{2}$-splitting, a large portion of the overall energy demand of the system is associated with heating the redox material from the oxidation temperature to the reduction temperature. Hence, an important measure to improve the efficiency is recuperation of sensible heat stored in the redox material. A solid-solid heat exchanger can be subject to undesirable oxygen crossover, which decreases the oxygen uptake capacity of the redox material and consequently the system efficiency. We investigate the extent of this crossover in ceria based cycles, to identify, under which conditions a heat exchanger that allows oxygen crossover can improve the system efficiency. In a thermodynamic analysis we calculate the amount of transferred oxygen as a function of the heat exchanger efficiency and show the system efficiency of such a concept. A second law analysis is applied to the model to check the feasibility of calculated points of operation. For the investigated parameter set the heat exchanger design improves the system efficiency by a factor of up to 2.1.
\end{abstract}

\section{KEYWORDS}

solar chemistry; water splitting; carbon dioxide splitting; redox cycle; solid-solid heat exchanger.

\section{INTRODUCTION}

Mitigation of anthropogenic greenhouse gas emissions is one of the most important challenges of our time. Nevertheless, combustion of carbon-based liquid fuels will likely continue to play an important role in the energy and transportation sectors, due to their high energy density. Two step-solar thermochemical redox cycles can close the carbon cycle and offer a promising approach for the production of carbon-neutral fuels. This technology uses a redox material to split $\mathrm{H}_{2} \mathrm{O}$ and $\mathrm{CO}_{2}$ for the production of $\mathrm{H}_{2}$ and $\mathrm{CO}$, which can be processed further to liquid fuels, e.g. via a Fischer-Tropsch synthesis [1].

\footnotetext{
${ }^{1}$ Contact author: Philipp.Holzemer-Zerhusen@dlr.de
}

A frequently investigated redox material is ceria [2-4]. Ceria shows a non-stoichiometric behavior, which means that oxygen vacancies are created or filled during reduction or oxidation of the material, respectively, while the lattice structure is stable over a wide range of oxidation/reduction states [5,6]. Ceria is a good oxygen ion conductor [7], which results in a fast oxidation/reduction kinetic [3, 8].

The oxidation of ceria and simultaneous production of $\mathrm{H}_{2}$ or $\mathrm{CO}$ is described by the following reaction equations:

$$
\begin{aligned}
& \mathrm{CeO}_{2-\delta_{\text {red }}}+\Delta \delta \mathrm{H}_{2} \mathrm{O} \rightarrow \mathrm{CeO}_{2-\delta_{\text {ox }}}+\Delta \delta \mathrm{H}_{2} \\
& \mathrm{CeO}_{2-\delta_{\text {red }}}+\Delta \delta \mathrm{CO}_{2} \rightarrow \mathrm{CeO}_{2-\delta_{\text {ox }}}+\Delta \delta \mathrm{CO},
\end{aligned}
$$

where $\Delta \delta=\delta_{\text {red }}-\delta_{o x}$. To regenerate the oxygen uptake capacity of ceria, it has to be reduced at high temperatures and low oxygen partial pressures, according to

$$
\mathrm{CeO}_{2-\delta_{\text {ox }}} \leftrightarrow \mathrm{CeO}_{2-\delta_{\text {red }}}+\frac{\Delta \delta}{2} \mathrm{O}_{2} .
$$

Typically, the reduction takes place at around $1773 \mathrm{~K}[2,9,10]$, whereas the oxidation is performed at significantly lower temperatures of typically $973-1373 \mathrm{~K}[2,7,11]$. The reduction reaction can be supported by lowering the oxygen partial pressure. Low oxygen partial pressures were achieved in experiments by either sweeping the reactor with an inert gas $[12,13]$ or by application of vacuum pumps [2].

The gap between oxidation and reduction temperature requires heating of the redox material before the reduction step. Marxer et al. show that the portion of this sensible heat constitutes approximately $60 \%$ of the overall heat demand of the process [2]. A solid-solid heat exchanger for heat recuperation between oxidized and reduced ceria is therefore an important measure to increase the system efficiency of two step redox cycles.

The need for solid-solid heat exchangers was expressed in several studies [2, 14-16] and different concepts have been 
proposed. Diver et al. [17] presented the counter-rotating ring receiver/reactor/recuperator (CR5). In this concept counterrotating parallel rings first move through the hot reduction zone and then through the cold oxidation zone. Due to the opposed rotation directions the rings can exchange heat. All rings move in a common atmosphere. During operation problems with material cracking and mass flow limitations occurred [18]. In numeric simulations a heat exchanger efficiency of up to $88 \%$ [19] was predicted, however heat exchanger efficiencies in experiments were below $1 \%$ [18]. A similar concept was proposed by Lapp et al. [20]. In their reactor design they also use counter rotating elements. The reactive material is a hollow cylinder rotating through the two reaction zones. Inside the cylinder, there is another concentric cylinder, made from inert material, which absorbs heat from the hot part of the reactive material and transfers it to colder regions. A numeric model predicts heat exchanger efficiencies of $41 \%$ or even above $50 \%$ if penalties such as a lower temperature of the reactive material are tolerated [20].

A heat recovery system for stationary monolith receiver reactors was introduced by Brendelberger et al. [15]. Here, a heat transfer fluid is used to transfer heat from the reactive material to a heat storage after the reduction and back after the oxidation. The theoretical work predicts heat savings of up to $40 \%$ for a single storage unit [15].

Like rotating systems, particle concepts allow continuous operation of the process. Richter et al. [21] and Felinks et al. [22] studied heat exchange between reactive particles and inert particles used as heat transfer medium. The utilization of heat transfer particles allows separation of oxidized and reduced particles. In theoretical studies the heat exchanger efficiency was estimated to reach more than $70 \%$ [22]. An approach without inert particles was presented by Ermanoski et al. [23]. Here, a screw elevator transports cold particles into the reduction zone, where they are heated. The hot particles then move in the opposite direction, inside the screw elevator, driven by gravity. The packed bed provides a separation of reduction and oxidation atmosphere. In experiments with quartz sand at temperatures up to $423 \mathrm{~K}$ the heat exchanger efficiency was in the range $25-50 \%$ [24].

Counter flow heat exchangers with a linear motion of the redox material were studied by Falter et al. [25-27]. They developed a generic model for estimation of heat exchanger efficiencies. A heat exchanger efficiency close to $70 \%$ results from their calculations [25]. In their model, they assume separation of the atmospheres, by a separation wall.

All concepts above, offer valuable insights into possible technical solutions to heat recovery in two step-solar thermochemical redox cycles. However, solid-solid heat exchangers also introduces an additional challenge to the process, which has so far not been studied extensively: In a direct heat exchanger the temperature change can cause a change in the oxidation state of the redox material and lead to an undesirable crossover of oxygen, in which oxygen is released by the heated oxidized material and absorbed by the cooled reduced material. We refer to this effect as recombination. Unless prevented by technical measures, recombination leads to a reduction of the oxygen uptake capacity of the redox material and consequently to a reduction of the system efficiency. However, measures to mitigate recombination such as a physical separation of the atmospheres of the two streams typically also limit the intended heat transfer.

Siegrist et al. [28] discuss whether a solid-solid heat exchanger can improve the system efficiency even if it allows recombination. In their concept, the moving brick receiver reactor (MBR2), redox material in the form of bricks is cycled between reduction and oxidation reactor and moves in linearly through a counter flow heat exchanger. The two reactors might be separated from the heat exchanger by pressure locks, but no separation of atmospheres within the heat exchanger is intended, hence recombination is not prevented. As a metric for recombination they introduce the recombination factor $f_{\text {recomb }}$ :

$$
f_{\text {recomb }}=\frac{\delta_{\text {red }}-\delta_{\text {red }, H X, o u t}}{\delta_{\text {red }}-\delta_{\text {ox }}}
$$

where $\delta_{\text {red,HX,out }}$ is the non-stoichiometry of reduced ceria after leaving the heat exchanger. They show that the overall system efficiency can be improved as long as the recombination extent is smaller than the heat exchanger efficiency. This is in good approximation given if $f_{\text {recomb }}<\eta_{H X}$ holds. However, the correlation of recombination and heat exchanger efficiency is yet to be studied. This raises the question, whether a solidsolid heat exchanger that allows recombination can actually be operated under conditions in which the net system efficiency is increased. Since in several heat recovery concepts the atmospheres of reduced and oxidized redox material are not separated and recombination is not prevented $[17,20,28]$ and in other concepts the separation of the atmospheres can never be perfect (e.g. ref. [23]), this question is of particular interest with respect to the system efficiency. In the present study we want to answer that question with a thermodynamic analysis of a reactor design based on the MBR2 concept. We model the system in Python 3.6 [29] and calculate the amount of transferred oxygen as a function of the heat exchanger efficiency. Furthermore, we compare the system efficiency of such a concept to the state of the art and the potential of an ideal heat exchanger. A second law analysis is applied to the model to check the feasibility of calculated points of operation.

\section{METHODS AND MODEL}

The studied system comprises the solid-solid heat exchanger $(\mathrm{HX})$, the reduction and oxidation chamber and pressure locks in between. A schematic of the system is given in Figure 1. Pressure locks are assumed to work ideally in the sense that they fully prevent the transport of gases and hence separate the atmospheres of two adjacent subsystems. They are represented 
by dashed lines in Figure 1. Pressure lock 1 suppresses oxygen transport between reduction chamber and HX. Pressure lock 2 prevents transport of product $\left(\mathrm{H}_{2}\right.$ or $\left.\mathrm{CO}\right)$ into the $\mathrm{HX}$, where it might reduce the just oxidized ceria at higher temperatures and react back to $\mathrm{H}_{2} \mathrm{O}$ or $\mathrm{CO}_{2}$. In this work we distinguish between two different pressure lock setups. Setup 1 contains both pressure locks, whereas setup 2 only contains pressure lock 2 . These pressure lock arrangements were discussed in ref. [28] based on very coarse assumptions and shall therefore be studied more thoroughly in the present study. In setup 1, the HX is isolated from the reaction chambers and the oxygen stream $\dot{n}_{\mathrm{O}_{2}}$ in Figure 1 does not exist in this setup. The resulting oxygen partial pressure in the HX is explained in detail below. In setup 2 there is no separation of $\mathrm{HX}$ and reduction chamber, so that the oxygen partial pressure is the same. A third setup in which only Pressure lock 1 exists is not considered, because of the aforementioned back reaction of product.

Furthermore, Figure 1 shows the thermodynamic states in the HX labeled 1 to 4 . These numbers are used as indices to reference to the corresponding point in Figure 1 (e.g. $T_{4}, \delta_{2}, \ldots$ ). The change in the oxidation state of ceria between two points is denoted as $\Delta \delta_{i j}$, which is defined as $\delta_{j}-\delta_{i}$. The system is modeled in Python 3.6 [29] describing heat and mass transfer and the chemical reactions.

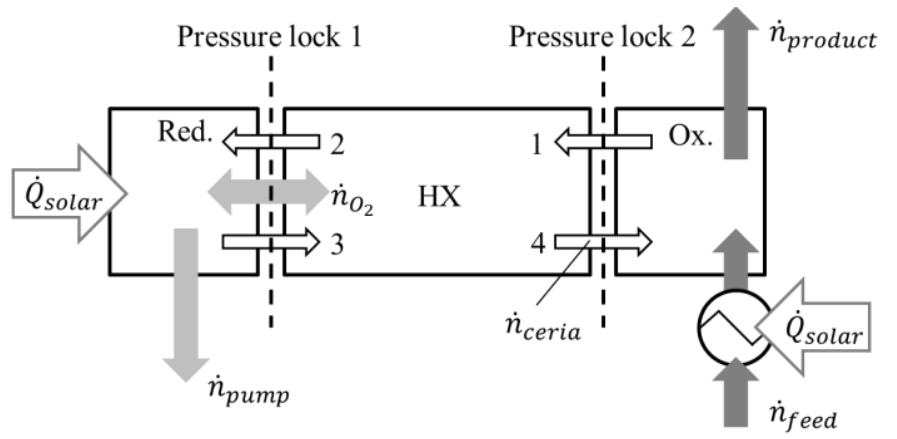

Figure 1: Schematic of the system.

\subsection{Reactions and mass transfer}

All reactions between ceria and the gas phase are assumed to reach their equilibrium. This assumption seems justified considering the fast kinetics mentioned above. In the reduction chamber the solar thermal reduction of ceria in vacuum operation is investigated. The utilization of sweep gas is not considered. The equilibrium of Reaction (1.3) and corresponding $\delta$-values are modelled with a correlation given by Bulfin et al. [4]. For the oxidation both $\mathrm{H}_{2} \mathrm{O}$ and $\mathrm{CO}_{2}$ splitting are considered and the equilibrium of the splitting reaction is determined. To do so, the reaction is separated into two parts. Firstly the splitting of $\mathrm{H}_{2} \mathrm{O}$ or $\mathrm{CO}_{2}$ into $\mathrm{H}_{2}$ or $\mathrm{CO}$ and molecular $\mathrm{O}_{2}$

$$
\mathrm{H}_{2} \mathrm{O} / \mathrm{CO}_{2} \leftrightarrow \mathrm{H}_{2} / \mathrm{CO}+\frac{1}{2} \mathrm{O}_{2}
$$

and secondly the oxidation of ceria with oxygen, which is also described by Reaction (1.3). The equilibrium of Reaction (2.1) is calculated with the law of mass action.

$$
K_{e q}=\frac{\frac{p_{H_{2}}}{p_{0}} \cdot\left(\frac{p_{O_{2}}}{p_{0}}\right)^{\frac{1}{2}}}{\frac{p_{H_{2} O}}{p_{0}}}
$$

where $p_{\mathrm{H}_{2}}, p_{\mathrm{O}_{2}}$ and $p_{\mathrm{H}_{2} \mathrm{O}}$ are partial pressures and $p_{0}$ is the standard pressure 1 bar. Due to the equivalent stoichiometry of $\mathrm{H}_{2} \mathrm{O}$ and $\mathrm{CO}_{2}$ splitting, $p_{\mathrm{H}_{2}}$ and $p_{\mathrm{H}_{2} \mathrm{O}}$ can be replaced by $p_{\mathrm{CO}_{2}}$ and $p_{\mathrm{CO}}$, respectively. Introducing the conversion of $\mathrm{H}_{2} \mathrm{O}$ or $\mathrm{CO}_{2}, X_{o x}$ and rearranging equation (2.2), the oxygen partial pressure in the oxidation chamber can be determined as

$$
p_{O_{2}, o x}=p_{0} \cdot\left(\frac{K_{e q} \cdot\left(1-X_{o x}\right)}{X_{o x}}\right)^{2} \text {. }
$$

$K_{e q}$ is determined as a function of the free gibbs energy of reaction according to

$$
K_{e q}=\exp \left(-\frac{\Delta_{R} G}{R \cdot T_{o x}}\right) .
$$

Here $\Delta_{R} G$ is calculated with data obtained from the software FactSage 7.0 [30]. The feed stream consisting of $\mathrm{H}_{2} \mathrm{O}$ or $\mathrm{CO}_{2}$ is

$$
\dot{n}_{f e e d}=\frac{\dot{n}_{\text {product }}}{X_{o x}},
$$

where $\dot{n}_{\text {product }}$ is the stream of pure $\mathrm{H}_{2}$ or $\mathrm{CO}$. The corresponding amount of ceria results from the amount of converted feed and the oxygen remaining in the product stream $\dot{n}_{\mathrm{O}_{2}, \mathrm{ox}}$ :

$$
\dot{n}_{\text {ceria }}=-\frac{\dot{n}_{f e e d} \cdot X_{o x}-2 \cdot \dot{n}_{O_{2}, o x}}{\Delta \delta_{41}},
$$

where $\dot{n}_{\mathrm{O}_{2}, \text { ox }}$ can be calculated according to

$$
\dot{n}_{\mathrm{O}_{2}, \mathrm{ox}}=\dot{n}_{\text {feed }} \cdot \frac{p_{\mathrm{O}_{2}, \mathrm{ox}}}{p_{\text {tot }, o x}-p_{\mathrm{O}_{2}, \mathrm{ox}}} .
$$

$p_{\text {tot,ox }}$ is the total pressure in the oxidation reactor.

For calculation of thermodynamic states in the HX the two pressure lock setups have to be distinguished. In setup 1 the partial oxygen pressure $p_{\mathrm{O}_{2}, \mathrm{HX}}$ has to be calculated. In the $\mathrm{HX}$ a stable state will establish in which $\Delta \delta_{12}=-\Delta \delta_{34}$, i.e. the amount of oxygen released by one ceria stream equals the amount of oxygen absorbed by the other ceria stream so that $p_{O_{2}, H X}$ is constant over time. In a scenario, where $\Delta \delta_{12} \neq$ $-\Delta \delta_{34}$, more oxygen would be released than taken up or vice versa and $p_{O_{2}, H X}$ would increase or decrease, respectively. Consequently, $p_{\mathrm{O}_{2}, \mathrm{HX}}$ will again reach its stable value, according to Figure 2. In case of setup 2, HX and reduction chamber share a common atmosphere and $p_{\mathrm{O}_{2}, \mathrm{HX}}$ is determined by the vacuum pump. Therefore, $p_{O_{2}, H X}=p_{O_{2}, \text { red }}$. The condition $\Delta \delta_{12}=-\Delta \delta_{34}$ does not have to hold for setup 2 . More oxygen might be released than taken up and then be 
removed by the vacuum pump or more oxygen is taken up than released in the HX and is then compensated with oxygen entering from or leaving to the reduction chamber.

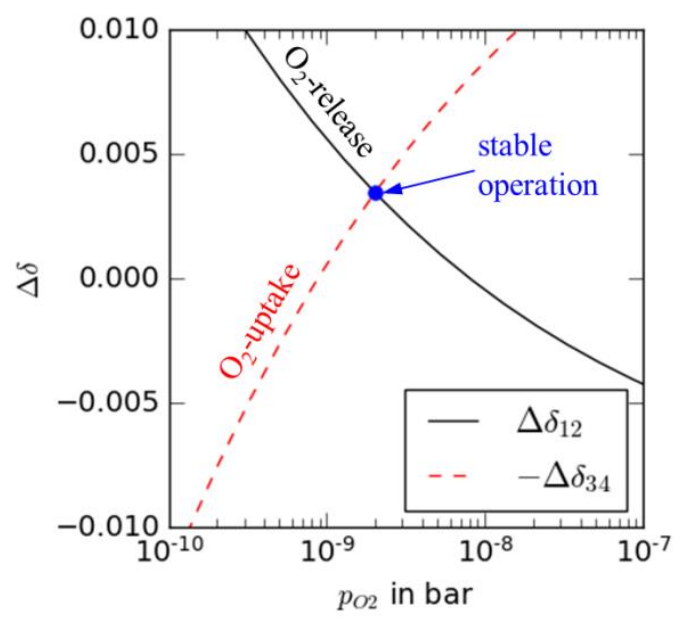

Figure 2: Stable point of operation for setup 1.

Table 1: Conditions at different states $i$ for both pressure lock setups. Quantities marked with a dagger are calculated in the model. Other quantities are given parameters.

\begin{tabular}{ccccc}
\hline State & \multicolumn{2}{c}{ Conditions - setup 1 } & \multicolumn{2}{c}{ Conditions - setup 2 } \\
$\boldsymbol{i}$ & $\boldsymbol{p}_{\boldsymbol{O}_{2}, \boldsymbol{i}}$ & $\boldsymbol{T}_{\boldsymbol{i}}$ & $\boldsymbol{p}_{\boldsymbol{O}_{2}, \boldsymbol{i}}$ & $\boldsymbol{T}_{\boldsymbol{i}}$ \\
\hline 1 & $f\left(X_{\text {ox }}\right)^{\dagger}$ & $T_{o x}$ & $f\left(X_{\text {ox }}\right)^{\dagger}$ & $T_{o x}$ \\
2 & $p_{O_{2}, H X}^{\dagger}$ & $f\left(\eta_{H X}\right)^{\dagger}$ & $p_{O_{2}, \text { red }}$ & $f\left(\eta_{H X}\right)^{\dagger}$ \\
3 & $p_{O_{2}, \text { red }}$ & $T_{\text {red }}$ & $p_{O_{2}, \text { red }}$ & $T_{\text {red }}$ \\
4 & $p_{O_{2}, H X}^{\dagger}$ & $f\left(\eta_{H X}\right)^{\dagger}$ & $p_{O_{2}, \text { red }}$ & $f\left(\eta_{H X}\right)^{\dagger}$ \\
\hline
\end{tabular}

A mass balance around control volume (CV) I in Figure 3 yields the oxygen stream removed by the vacuum pumps

$$
\dot{n}_{O_{2}, \text { pump }}=-\frac{1}{2} \Delta \delta_{41} \cdot \dot{n}_{\text {Ceria }} \text {. }
$$

The oxygen stream exchanged between $\mathrm{HX}$ and reduction chamber can be derived by a mass balance around CV II:

$$
\dot{n}_{O_{2}}=\frac{1}{2} \Delta \delta_{23} \cdot \dot{n}_{\text {Ceria }}-\dot{n}_{O_{2}, \text { pump }},
$$

where $\dot{n}_{O_{2}}>0$ corresponds to a flow entering the HX. For setup $1 \Delta \delta_{23}=-\Delta \delta_{41}$ and hence $\dot{n}_{O_{2}}=0$. From Equations (2.8) and (2.9),

$$
\dot{n}_{O_{2}}=\frac{1}{2}\left(\delta_{1}-\delta_{2}+\delta_{3}-\delta_{4}\right) \cdot \dot{n}_{\text {ceria }}
$$

follows. For convenience, we introduce the quantity $\Delta \delta^{*}=$ $\delta_{1}-\delta_{2}+\delta_{3}-\delta_{4}$. The degree of recombination is given by the recombination factor. According to our nomenclature it is defined as

$$
f_{\text {recomb }}=\frac{\Delta \delta_{34}}{\Delta \delta_{31}}
$$

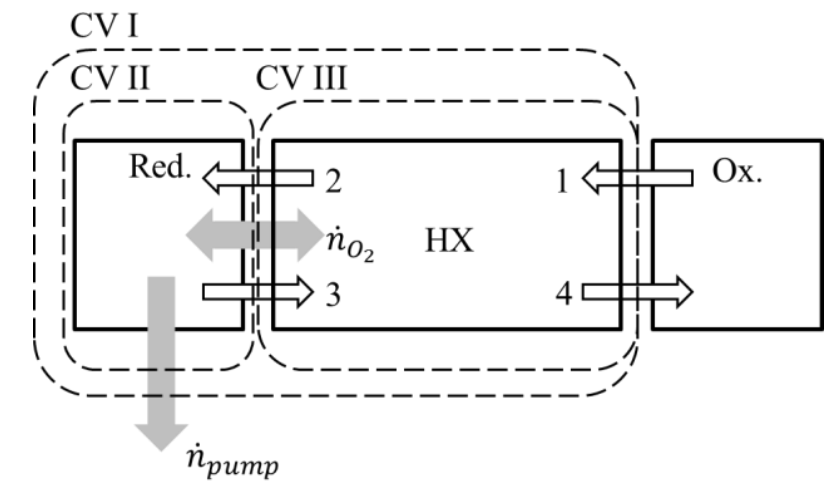

Figure 3: Simplified scheme of the concept with control volumes for balance equations.

\subsection{Efficiency and energy demand}

The temperatures of streams leaving the HX, namely $\mathrm{T}_{2}$ and $\mathrm{T}_{4}$ correlate with the HX-efficiency $\eta_{H X}$, which is defined as

$$
\eta_{H X}=\frac{\int_{T_{1}}^{T_{2}} c_{p, \text { ceria }} d T}{\int_{T_{1}}^{T_{3}} c_{p, \text { ceria }} d T} .
$$

An energy balance around the HX (CV III) in steady state operation yields

$$
\begin{gathered}
0=\dot{n}_{\text {ceria }}\left(-\int_{T_{1}}^{T_{2}} c_{p, \text { ceria }} d T-\int_{T_{3}}^{T_{4}} c_{p, \text { ceria }} d T\right. \\
-\Delta_{R} h_{12}-\Delta_{R} h_{34} \\
\left.\quad+\frac{1}{2} \Delta \delta^{*} \int_{T_{0}}^{T_{O_{2}}} c_{p, O_{2}} d T\right)
\end{gathered}
$$

where $\Delta_{R} h_{i j}$ is the heat of reaction per mole ceria related to the reduction and oxidation of the two streams in the HX. In case of a net reduction $\left(\Delta \delta^{*}<0\right)$ in the $\mathrm{HX}$, the integral over $c_{p, O_{2}}$ accounts for heating the oxygen stream after the reaction at $T_{0}$ to $T_{O_{2}}$. In case of a net oxidation $\left(\Delta \delta^{*}>0\right)$ an oxygen stream enters the $\mathrm{HX}$ and adds heat to $\mathrm{CV}$ III. We assume $T_{O_{2}}=$ $\frac{1}{2}\left(T_{2}+T_{3}\right)$ for a leaving stream and $T_{O_{2}}=T_{3}$ for an entering stream. $T_{0}$ is the reference temperature at which the reaction takes place and lies between $T_{1}$ and $T_{3}$. For setup 1 the extent of reduction and oxidation are equal and the reaction enthalpies offset. For the same reason $\Delta \delta^{*}=0$. Therefore, by combining Equations (2.12) and (2.13) $T_{4}$ can be calculated according to

$$
\int_{T_{3}}^{T_{4}} c_{p, \text { ceria }} d T=-\eta_{H X} \int_{T_{1}}^{T_{3}} c_{p, \text { ceria }} d T .
$$

$T_{2}$ follows from Equation (2.12). For setup 2 we find that the expression accounting for $\mathrm{O}_{2}$ in Equation (2.13) is negligible. Since $\Delta_{R} h_{i j}$ depends on the temperatures and the temperatures depend on $\Delta_{R} h_{i j}$, Equation (2.13) theoretically needs an iterative solution for setup 2. However, a coarse estimation implies that the error made by neglecting $\Delta_{R} h_{i j}$ is tolerable, so we use Equation (2.14) for both pressure lock setups. Heat losses from the HX to the ambience are not considered. 
The heat capacity $c_{p, c e r i a}$ is calculated with data from Touloukian [31]. It is modelled as a function of the temperature, but not of the non-stoichiometry. To reach the reduction temperature $T_{3}$ heat, which is not recuperated has to be supplied by the solar flux and is calculated by

$$
\dot{Q}_{c e r i a}=\dot{n}_{c e r i a} \cdot\left(1-\eta_{H X}\right) \int_{T_{1}}^{T_{3}} c_{p, c e r i a} d T .
$$

Furthermore, the heat of reduction in the receiver reactor is

$$
\dot{Q}_{\text {reduction }}=\dot{n}_{\text {ceria }} \cdot \int_{\delta_{2}}^{\delta_{3}} \Delta_{\delta} h(\delta) d \delta,
$$

where $\Delta_{\delta} h(\delta)$ is the heat of Reaction (1.3) per increment of $\delta$. We use an equation by Bulfin et al. [32], who fit a polynomial to data from Panlener et al. [5]. Panlener et al. [5] found that $\Delta_{\delta} h$ is in good approximation independent of the temperature for the relevant $\delta$-range. Heat for pre-heating of the feed stream is determined by

$$
\begin{aligned}
\dot{Q}_{\text {feed }}= & \dot{n}_{f e e d} \cdot\left(h_{\mathrm{H}_{2} \mathrm{O}, \text { gas }}\left(T_{1}\right)\right. \\
& \left.-h_{\mathrm{H}_{2} \mathrm{O}, \mathrm{liq}}\left(T_{a m b}\right)\right),
\end{aligned}
$$

in case of $\mathrm{H}_{2} \mathrm{O}$ splitting or in case of $\mathrm{CO}_{2}$ splitting:

$$
\dot{Q}_{f e e d}=\dot{n}_{f e e d} \cdot\left(h_{\mathrm{CO}_{2}}\left(T_{1}\right)-h_{\mathrm{CO}_{2}}\left(T_{a m b}\right)\right) .
$$

Herein $h_{i}$ is the molar enthalpy of component $i$, calculated with data from FactSage, $T_{a m b}=298 \mathrm{~K}$ is the ambient temperature. In Equation (2.17) the heat of evaporation is considered.

For the vacuum pumps we use a three stage pump array consisting of two HV40000, one HV8000 and two IDX1300 pumps by Edwards as described by Brendelberger et al. [33]. The volume flow that such an array removes from the reduction chamber at $p_{\text {red }}$ is called $\dot{V}_{\text {array }}$ and the pumping power needed to remove $\dot{V}_{\text {array }}$ at $p_{\text {red }}$ is $P_{\text {array }}$. Both $\dot{V}_{\text {array }}$ and $P_{\text {array }}$ are calculated with data from Brendelberger et al. [33]. Scaled to 1 $\mathrm{mol} / \mathrm{s}$ of product the pumping power is

$$
P_{\text {pump }}=\frac{\dot{V}_{\text {pump }}}{\dot{V}_{\text {array }}} \cdot P_{\text {array }},
$$

where $\dot{V}_{\text {pump }}$ is the volume flow removed from the reduction chamber per mol/s of product. It is calculated using the ideal gas law, which seems justified, with respect to the low pressures:

$$
\dot{V}_{\text {pump }}=\dot{n}_{O_{2}, p u m p} \cdot \frac{R \cdot T_{a m b}}{p_{\text {red }}} .
$$

The removed oxygen is cooled to ambient temperature before passing the pump array. The electrical power to supply the pumps is considered to come from a CSP power plant. Xu et al. [34] determined the electrical efficiency of such a power plant to be $\eta_{e l}=0.257$. We take their value of the total efficiency excluding the field efficiency as we determine the system efficiency from receiver to product, so that $\eta_{e l}=0.343$ in our model.

As shown in Figure 1, a solar flux is not only used to heat the reduction chamber, but also to preheat and (in case of water) evaporate the feed stream. Heat recuperation in the gas phase is not studied, since it only is a small portion of the overall heat demand (1.8\% for $\mathrm{CO}_{2}$-splitting and $3.4 \%$ for $\mathrm{H}_{2} \mathrm{O}$-splitting). Consequently there are two receivers, operating at different temperatures, $T_{\text {red }}$ and $T_{o x}$. The resulting receiver efficiency is

$$
\eta_{\text {rec }}=1-\frac{\varepsilon \cdot \sigma \cdot\left(T_{\text {rec }}^{4}-T_{a m b}^{4}\right)}{\dot{q}_{\text {solar }}^{\prime \prime}},
$$

where $\varepsilon$ is the receiver's emissivity, $\sigma$ is the Stefan-Boltzmann constant and $\dot{q}_{\text {solar }}^{\prime \prime}$ is the solar flux, reaching the aperture from the heliostat field. The overall energy demand of the process is

$$
\dot{Q}_{\text {solar }}=\frac{P_{\text {pump }}}{\eta_{\text {el }}}+\frac{\dot{Q}_{\text {ceria }}+\dot{Q}_{\text {red }}}{\eta_{\text {rec }, \text { red }}}+\frac{\dot{Q}_{\text {feed }}}{\eta_{\text {rec }, \text { ox }}} .
$$

And the system efficiency is

$$
\eta_{\text {sys }}=\frac{\dot{n}_{\text {product }} \cdot H H V_{\text {product }}}{\dot{Q}_{\text {solar }}},
$$

with the HHV of the product $\left(\mathrm{CO}\right.$ or $\left.\mathrm{H}_{2}\right)$ found in [35].

\subsection{Entropy balance}

Under certain conditions mass balances allow for results that contradict the second law of thermodynamics. To identify those conditions, we introduce an entropy balance of CV III that enables us to do a second-law-analysis of the system. The general entropy balance for a steady state system is [36]:

$$
\frac{\partial S}{\partial t}=0=\sum_{i} \frac{\dot{Q}_{l}}{T_{i}}+\sum_{i} \dot{n}_{i} \cdot s_{i}+\Delta \dot{S}_{i r r}
$$

Since we do not account for heat losses from the HX to the ambience and the heat transferred within the HX does not cross the boundaries of CV III, there are no heat streams $\dot{Q}_{i}$. For the studied system the balance reads

$$
\begin{gathered}
0=\dot{n}_{\text {Ceria }} \cdot\left(s_{1}-s_{2}+s_{3}-s_{4}\right)+\dot{n}_{O_{2}} \cdot s_{O_{2}} \\
+\Delta \dot{S}_{i r r} .
\end{gathered}
$$

For simplicity we introduce $\Delta s_{i r r}=\Delta \dot{S}_{i r r} / \dot{n}_{\text {Ceria }}$. Using Equation (2.10), we get

$$
\Delta s_{i r r}=s_{2}-s_{1}+s_{4}-s_{3}-\frac{1}{2} \Delta \delta^{*} \cdot s_{O_{2}} .
$$

The status change of a ceria stream in the HX, including chemical change and heating/cooling is separated in three steps according to Figure 4: Firstly, the (hypothetical) oxidation from $\delta_{1}$ or $\delta_{3}$ to $\delta=0$. at $T_{1}$ or $T_{3}$. Secondly, the temperature change from $T_{1}$ or $T_{3}$ to $T_{2}$ or $T_{4}$ at $\delta=0$. Thirdly, the (hypothetical) reduction to $\delta_{2}$ or $\delta_{4}$.

Each entropy in (2.26) consists of a chemical part and a thermal part, according to

$$
s_{i}(T, \delta)=s_{f, i}\left(T_{0}, \delta\right)+\Delta s_{t h}\left(T, T_{0}, \delta\right),
$$

where $T_{0}$ is a reference temperature, $s_{f, i}$ is the entropy of formation of material $i$ and $\Delta s_{t h}$ is the entropy change, related to heating or cooling from $T_{0}$ to $T$. The $\delta$-dependence in Equation (2.27) applies for ceria, however the entropy of $\mathrm{O}_{2}$ can be expressed in the same way. 


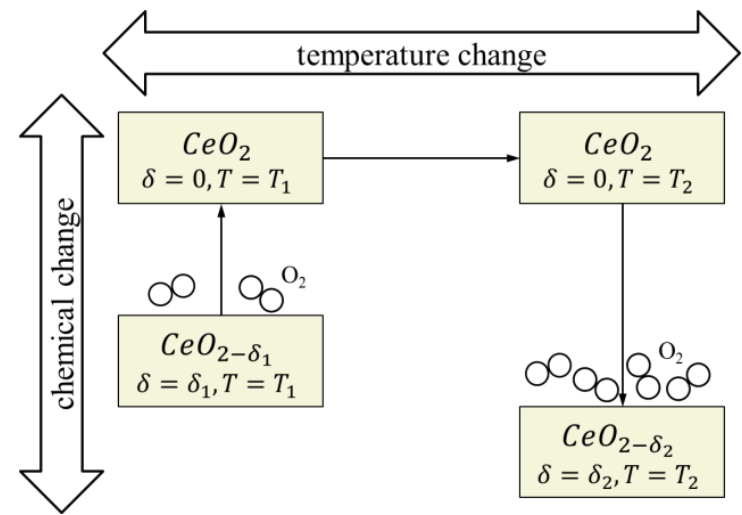

Figure 4: Visualization of the entropy change in the HX, shown exemplarily for the change of state 1 to state 2.

When substituting Equation (2.27) into (2.26), the entropies of formation add up to the entropy of reaction $\Delta_{R} S_{i j}$ and the thermal entropy change can be combined to $\Delta s_{i j, t h}$, which yields

$$
\begin{gathered}
\Delta s_{\text {irr }}=\Delta_{R} s_{12}+\Delta_{R} s_{34}+\Delta s_{12, t h}+\Delta s_{34, t h} \\
-\frac{1}{2} \Delta \delta^{*} \cdot \Delta s_{O_{2}, t h} .
\end{gathered}
$$

The expression $\Delta s_{O_{2, t h}}$ accounts for the entropy loss or input due to the leaving or entering mole flow $\dot{n}_{O_{2}}$. For the relevant temperature range, the temperature dependence of $\Delta_{R} s_{i j}$ is relatively weak [37]. It is calculated according to:

$$
\Delta_{R} s_{i j}=\int_{\delta_{i}}^{\delta_{j}} \Delta_{\delta} s\left(\delta, T_{0}\right) d \delta,
$$

where $\Delta_{\delta} S$ is the entropy of reduction or oxidation per increment of $\delta$ based on ref. [37]. The reference temperature $T_{0}=1423 \mathrm{~K}$ is the temperature for which Bulfin et al. determined $\Delta_{\delta} S$. Heating and cooling is accounted for by $\Delta s_{i j, t h}=s\left(T_{j}\right)-s\left(T_{i}\right)$ with values for the entropy of $\mathrm{O}_{2}$ from ref. [38] and ceria from ref. [39]. The entropy of $\dot{n}_{O_{2}}$ is $\Delta s_{O_{2}, t h}=s_{O_{2}}\left(T_{O_{2}}\right)-s_{O_{2}}\left(T_{0}\right)$, because the reaction is calculated at $T_{0}$ and $T_{O_{2}}$ is the temperature at which $\mathrm{O}_{2}$ enters or leaves the HX. In setup 1, no oxygen enters or leaves the HX and $\Delta \delta^{*}=0$ in Equation (2.28).

\section{RESULTS AND DISCUSSION}

First we define a set of parameters for our study. Values are given in Table 2. Parameters are chosen such that they roughly match experimental parameters by Marxer et al. [40]. The modelled system is a continuous process, in which ceria is cycled between two reactors, whereas the aforementioned experimental setup comprises a single reactor with a stationary monolithic ceria structure. Nonetheless, such parameters seem to be a good starting point for our investigations. The solar heat flux is set to $2500 \mathrm{~kW} / \mathrm{m}^{2}$. No heat losses from the HX to the ambience are considered. Incomplete heat exchange, i.e. $\eta_{H X}<1$ is therefore not a consequence of heat losses, but a deliberate constructional adjustment. This way we can study if an undersized $\mathrm{HX}$ is an interesting option to increase the system efficiency, since a small $\eta_{H X}$ is a possible measure to counteract recombination.

Table 2: Parameters for simulations.

\begin{tabular}{ccc}
\hline Parameter & Meaning & Value \\
\hline$X_{o x}$ & Conversion of $\mathrm{H}_{2} \mathrm{O}$ or $\mathrm{CO}_{2}$ in oxidation & chamber \\
$p_{\text {red }}$ & $\mathrm{O}_{2}$ partial pressure in reduction chamber & $10^{-3} \mathrm{bar}$ \\
$T_{\text {ox }}$ & Temperature in oxidation chamber & $1073.15 \mathrm{~K}$ \\
$T_{\text {red }}$ & Temperature in reduction chamber & $1773.15 \mathrm{~K}$ \\
$p_{\text {total,ox }}$ & Total pressure in oxidation chamber & 1.01325 \\
$T_{\text {amb }}$ & Ambient temperature & bar \\
$\dot{q}_{\text {solar }}^{\prime \prime}$ & Solar heat flux reaching the aperture & $298.15 \mathrm{~K}$ \\
$\eta_{\text {el }}$ & Efficiency of solar power plant & $\mathrm{kW} / \mathrm{m}^{2}$ \\
& & 0.343 \\
\hline
\end{tabular}

\subsection{System efficiency}

Results of the simulation for setup 1 are depicted in Figure 5. The plot shows two reference cases: A system without HX and a system with an ideal HX in which no recombination occurs $\left(f_{\text {recomb }}=0\right)$. The system efficiency of setup 1 first increases with the HX-efficiency, before it decreases for $\eta_{H X}>0.33$ and drops to 0 at $\eta_{H X}=0.55$. This behavior can be explained by the superposition of two effects: the increase of $\eta_{H X}$ decreases the sensible heat demand of the system. At the same time it increases the temperature change achieved in the HX which in turn increases the recombination effect. This is shown in Figure 6. Since the recombination increases in a non-linear fashion, it dominates the benefits of a $\mathrm{HX}$ at a certain point.

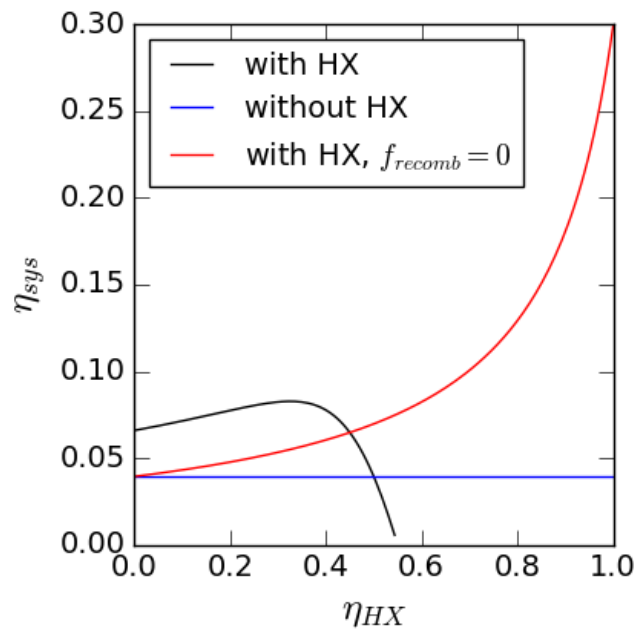

Figure 5: System efficiency as a function of the heat exchanger efficiency for setup 1 .

At $\eta_{H X}=0.5$ the efficiency of the system with HX equals that of the system without HX. As shown in Figure 6, here $\eta_{H X}=$ $f_{\text {recomb }}$ and the two effects offset. Reason for this is that if $50 \%$ of the heat is exchanged both streams leave the HX at the same temperature, i.e. $T_{2}=T_{4}$ and hence $\delta_{2}=\delta_{4}$. Since for setup $1 \Delta \delta_{12}=-\Delta \delta_{34}$ must hold, $\left|\Delta \delta_{34}\right|=\frac{1}{2} \Delta \delta_{13}$ follows. In 
other words: half of the oxygen capacity is lost due to recombination.

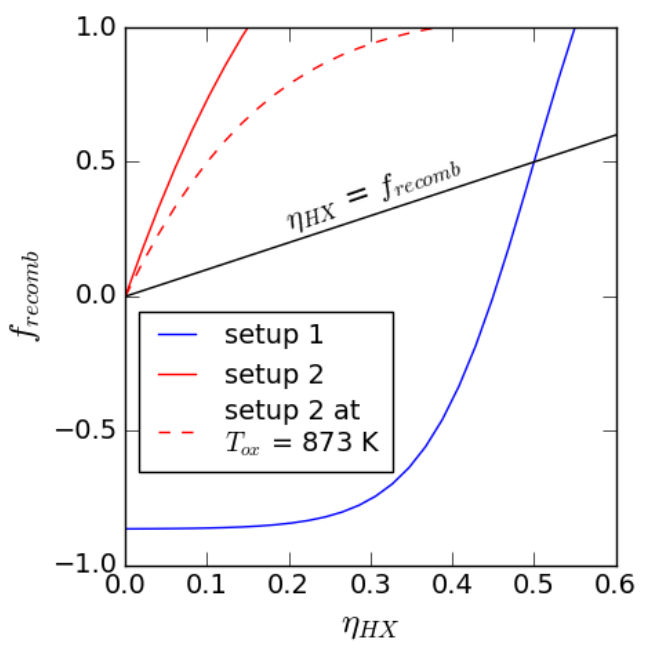

Figure 6: Recombination factor as a function of the heat exchanger efficiency. The black line shows points at which $\eta_{H X}=f_{\text {recomb }}$, so that the energy savings due to the HX and the recombination effect offset. For points below that line the $\mathrm{HX}$ improves the system efficiency and for points above the line, the $\mathrm{HX}$ reduces the system efficiency.

At higher $\eta_{H X}$ the system efficiency continues to decrease until it reaches zero at $\eta_{H X}=0.55$. At this point, $f_{\text {recomb }}$ becomes 1 as depicted in Figure 6 and the redox stream has no capacity to split water $\left(\Delta \delta_{14}=0\right)$. In general this point is reached well below $\eta_{H X}=1$, because $p_{O_{2}, H X}>p_{O_{2}, o x}$ and therefore the material can be oxidized in the HX to the same level as in the oxidation chamber, even if the material is not fully cooled down to $T_{o x}$. This happens at $\eta_{H X}=0.55$. Higher values of $\eta_{H X}$ are not discussed in this section, since water or carbon dioxide splitting is not possible.

Another remarkable observation is that the results of setup 1 can lead to a system efficiency higher than that of the system without recombination. To understand this result we show two exemplary sets of thermodynamic states in Figure 7. The four lines given in the diagrams are isothermals of the temperatures in the oxidation and reduction chamber and the HX outlets (states $1-4)$. Figure 7 (a) shows the result achieved at $\eta_{H X}=$ 0.48 . The outcome is as expected: the cold ceria stream from the oxidation chamber is reduced (black to blue point) and the hot ceria stream from the reduction chamber is oxidized (red to green point). In this case recombination reduces the system efficiency. A case in which the calculated efficiency of the investigated setup is higher than that of the ideal system is shown in Figure 7 (b) for $\eta_{H X}=0.2$. Here we find the recombination to be reversed, i.e. the cold ceria stream from the oxidation chamber is oxidized further in the HX, while the hot stream is reduced. The oxygen capacity of the material is higher than without recombination and less ceria is needed to produce the same amount of $\mathrm{H}_{2}$ or $\mathrm{CO}$. This unexpected change in the oxidation states is caused by the oxygen partial pressure in the
HX, which is higher than that of the oxidation chamber and lower than that of the reduction chamber. The partial pressure change counteracts the effect of temperature change, which is weak at low $\eta_{H X}$.

The feasibility of reversed recombination as well as all other points of operation is studied in a second law analysis, which is described in detail below. With respect to a system without HX, setup 1 increases the system efficiency by a factor of up to 1.6, if reversed recombination is not considered or up to 2.1 if reversed recombination is considered.
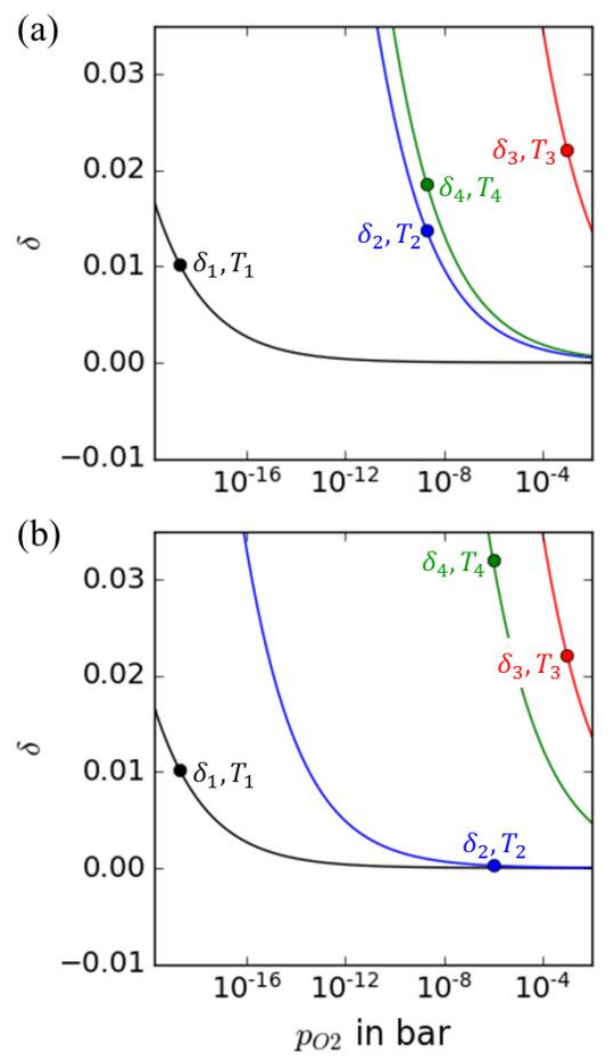

Figure 7: Thermodynamic states in the HX. Lines represent isotherms at the corresponding temperature. (a) setup 1 at $\eta_{H X}=0.48$, (b) setup 1 at $\eta_{H X}=0.2$.

Applying the parameters of Table 2 on setup 2 results in Figure 8 (a). The heat exchange in this setup leads to a decrease of the efficiency at all relevant points of operation. As discussed later we find that the results for setup 2 with this parameter set violate the second law for all points of operation. Decreasing the oxidation temperature $T_{o x}$ to $873 \mathrm{~K}$ leads to the results in Figure $8(\mathrm{~b})$. For these results the second law holds and the efficiency is somewhat improved. However the efficiency is still lower than without HX. This is caused by the large amount of recombination. Figure 6 shows that $f_{\text {recomb }}>\eta_{H X}$ for all $\eta_{H X}$, regardless of $T_{o x}$. In addition, $f_{\text {recomb }}=1$ is reached at lower $\eta_{H X}$ than in setup 2. A vivid explanation for the poor performance of this setup is that oxygen, which is released in the reduction chamber is not separated from the HX where it is again absorbed in vast amounts by the reduced redox material. 
This is in agreement with Figure 9, where both ceria streams in the HX appear to be oxidized with the oxygen from the reduction chamber.
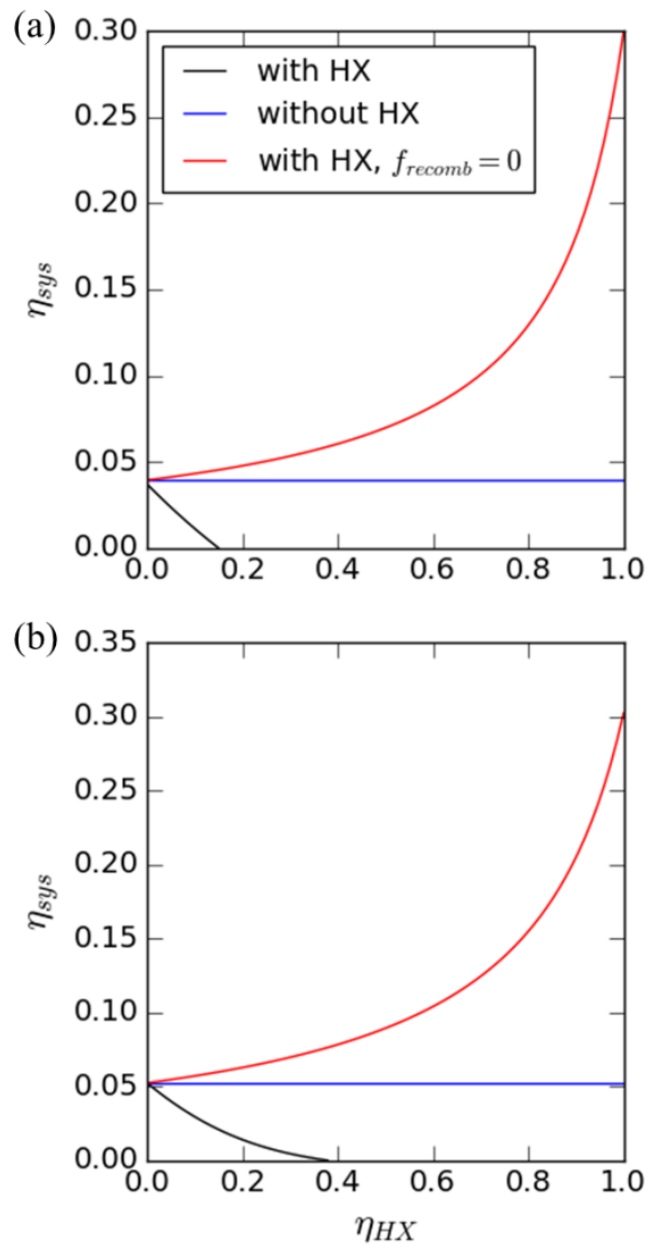

Figure 8: System efficiency as a function of the heat exchanger efficiency for setup 2. (a) parameters of Table 2, (b) $T_{o x}=873 \mathrm{~K}$, all other parameters are the same as in Table 2.

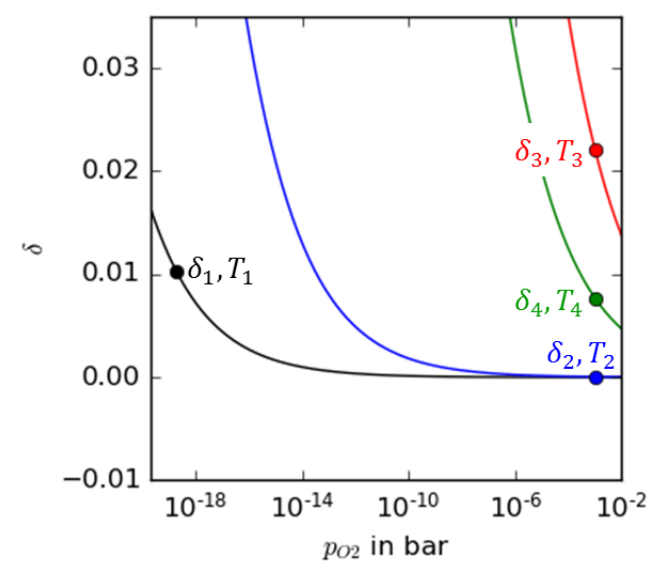

Figure 9: Thermodynamic states in the $\mathrm{HX}$ for setup 2 at $\boldsymbol{\eta}_{H X}=$ 0.2 . Lines represent isotherms at the corresponding temperature.
So far all results were shown for $\mathrm{H}_{2} \mathrm{O}$ splitting. However the general argumentation is valid for $\mathrm{CO}_{2}$ splitting as well. For the parameters given in Table 2, only minor differences occur between the two process variations, while the trend is the same for all results shown. These minor differences result from different thermodynamic data, which is used to calculate $H H V$, $\Delta_{R} G$ and $\dot{Q}_{f e e d}$. The biggest difference is that preheating $\mathrm{CO}_{2}$ does not require evaporation as for $\mathrm{H}_{2} \mathrm{O}$, which leads to smaller $\dot{Q}_{\text {feed }}$. Nevertheless, the overall efficiency of $\mathrm{H}_{2} \mathrm{O}$ and $\mathrm{CO}_{2}$ splitting is still similar since $\dot{Q}_{\text {feed }}$ has a relatively small impact on the total energy demand at $X_{o x}=0.6$. This is depicted in Figure 10 (a). Also the states shown in Figure 7 are similar for $\mathrm{H}_{2} \mathrm{O}$ and $\mathrm{CO}_{2}$ in that case. Nevertheless, choosing a different set of parameters might result in more significant deviation of $\mathrm{H}_{2} \mathrm{O}$ and $\mathrm{CO}_{2}$ splitting, as shown in Figure 10 (b) for $T_{o x}=$ $1273 \mathrm{~K}$ and $X_{\text {ox }}=0.2$.
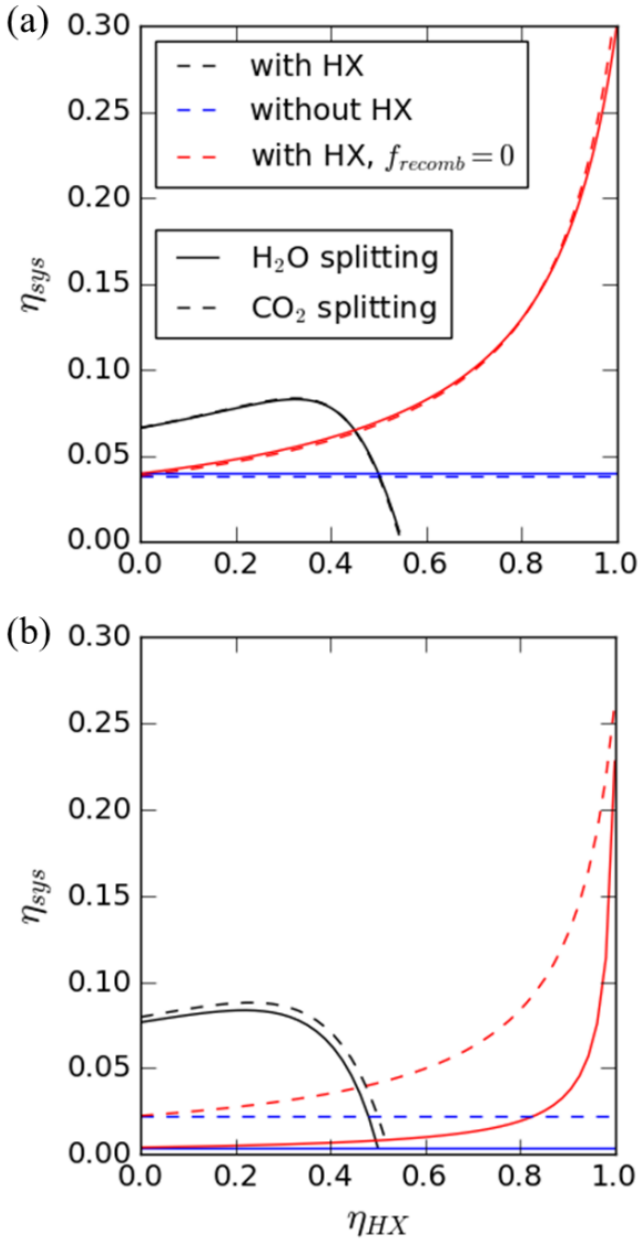

Figure 10: Comparison of $\mathrm{H}_{2} \mathrm{O}$ and $\mathrm{CO}_{2}$ splitting. The plots show the system efficiency as a function of the heat exchanger efficiency

for setup 1. (a): all parameters as in Table 2. (b): $\boldsymbol{T}_{o x}=$

1273. $15 K, X_{o x}=0.2$, all other parameters as in Table 2.

One reason is the temperature dependence of $\Delta_{R} G$, which favors $\mathrm{CO}_{2}$ over $\mathrm{H}_{2} \mathrm{O}$ splitting at higher $T_{o x}$. The oxidation 
temperature cannot be increased freely. High values can result in $\Delta \delta_{o x}>\Delta \delta_{\text {red }}$. To avoid this, we decreased $X_{o x}$ to 0.2 . Since this increases the $\mathrm{H}_{2} \mathrm{O}$ or $\mathrm{CO}_{2}$ feed, it also increases $\dot{Q}_{f e e d}$. As explained above, $\dot{Q}_{f e e d}$ might be different for the two process alternatives. All in all $\mathrm{H}_{2} \mathrm{O}$ and $\mathrm{CO}_{2}$ splitting might show different performances, however for our parameter set the results are very similar.

\subsection{Second law analysis}

Our model is a simplified representation of the system, which offers a first estimation of the recombination effect. Simplifications are amongst others infinite reaction rates, fast oxygen transport in the HX that results in an ideally mixed atmosphere and the negligence of heat losses from the HX to the ambience. Under certain conditions such simplifications might lead to unphysical results. Therefore, we use the entropy balance in (2.28) to check whether a point of operation obeys the second law.

For setup 1 we find that for low $\eta_{H X}$ the second law is violated. In this region the irreversible entropy production $\Delta s_{\text {irr }}<0$, as shown in Figure 11(a). For higher values of $\eta_{H X}$ the results obey the second law according to our entropy balance, even at points where the recombination is reversed. Here, the entropy production due to the chemical part $\Delta s_{\text {chem }}$ is negative, but it is compensated by the thermal part $\Delta s_{t h}$. The entropy balance that we use is a global balance around the HX. Such a balance can only show whether a simultaneous change from state 1 to state 2 and from state 3 to state 4 is possible. It does not show if the second law holds for every point in the HX along the flow direction. To proof that a continuous HX can be built that will actually reach these thermodynamic states, entropy balances for every element of the HX would be needed. Such an entropy balance yields the criterion $\left(\Delta_{\delta} h(\delta)-T \cdot \Delta_{\delta} s(\delta)\right) d \delta<0$, which equals a Gibb's criterion as introduced by Li et al. [41]. This task goes beyond the scope of the present study as we did not resolve the model in space.

As mentioned above, at $\eta_{H X}=0.55$ no water or carbon dioxide can be split as ceria is already fully oxidized by recombination in the HX. An entropy balance in the form of Equation (2.28) allows $\eta_{H X}>0.55$, as can be seen in Figure 11(a). Here, $\Delta s_{\text {irr }}>0$ still holds, however $\dot{n}_{\text {ceria }}<0$, which means that the whole process is reversed in its direction. In other words, the attended water or carbon dioxide splitting process is not feasible. Instead Equation (2.28) yields that a backward process would occur. Again, the entropy balance only covers the net change in the HX and no statement on the whole process can be made. On top of that a backward process is not of particular interest and will not be discussed further. A violation of the second law is found at very high $\eta_{H X}$.

For setup 2 the model reveals a violation of the second law for all points of operation for the parameters given in Table 2 .
Feasibility can only be reached after reduction of $T_{o x}$. The difference in the entropy for $T_{o x}=1073 \mathrm{~K}$ and $T_{o x}=873 \mathrm{~K}$ is displayed in Figure 11(b). As shown in Equation (2.28) for setup 2 there is also an expression $\Delta s_{\mathrm{O}_{2}}$, which covers the entropy of heating gaseous oxygen. This is however negligible compared to the other contributions to the entropy. Figure 11(b) shows that $T_{o x}$ has an impact on both the chemical and the thermal part of $\Delta s_{i r r}$. The impact of a lower $T_{o x}$ on the chemical part mainly results from a decreased $\delta_{1}$. At the same time the overall temperature level of the cold ceria stream in the HX is lower. Consequently, the thermal part varies as well. Setup 2 at $T_{o x}=873 K$ behaves similar to setup 1: only for very low and very high $\eta_{H X}$ the second law is violated.
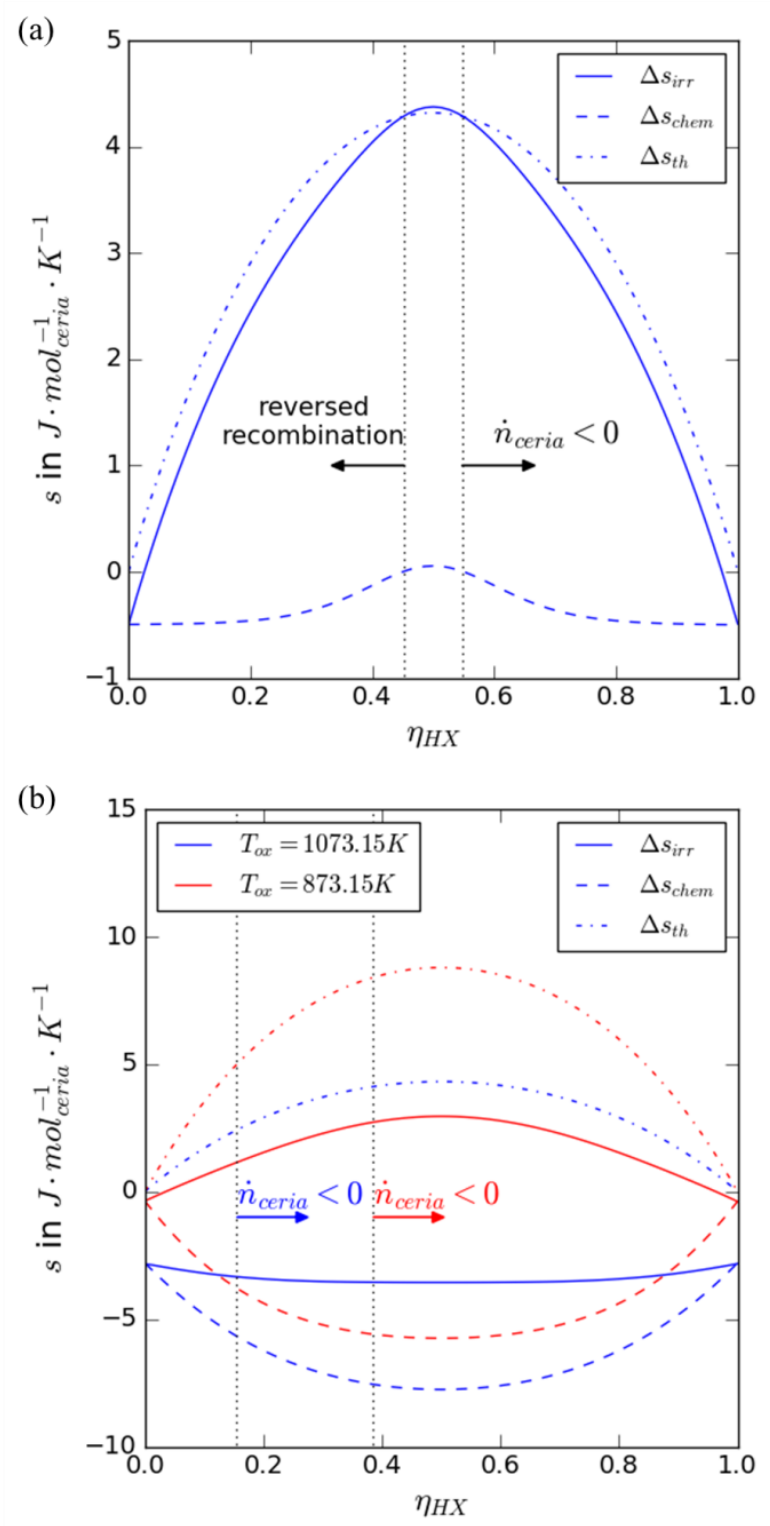

Figure 11: Entropy production as a function of the HX-efficiency for (a) setup 1 and (b) $\operatorname{setup} 2$ at $T_{o x}=1073 \mathrm{~K}$ and $T_{o x}=873 \mathrm{~K}$. 


\subsection{Measures to counteract recombination}

Up to this point we show that an HX in setup 1 can improve the system efficiency. At the same time we find that an ideal HX without recombination could lead to even higher efficiencies, if high $\eta_{H X}$ can be achieved. This raises the question, whether it is possible to achieve a performance closer to that of the ideal HX. In this section we therefore want to discuss options to mitigate recombination.

One approach is to suppress recombination by kinetic limitation of the oxygen transfer, which consists of three mechanisms:

1. Transport of oxygen-ions within the lattice of the redox material,

2. Surface reaction, i.e. reduction or oxidation of the redox material,

3. Transport of gaseous oxygen through the atmosphere in the HX.

First of all it shall be mentioned that in our model we assume the redox material to reach its equilibrium state at the HX outlet, which implies the three aforementioned mechanisms to be infinitely fast. The limited kinetics of a real system contributes to mitigation of recombination, which might be enhanced by technical measures. Ideally, the oxygen transport is limited in the HX but not in the reactors where it is needed to reach high degrees of reduction and oxidation, respectively. This makes acting on the first and second mechanism difficult. Changing the material thickness could be an option to influence mechanism 1, it is however not clear if this measure increases the efficiency due to better HX performance or rather decreases the efficiency due to worse reactor performance.

Mechanism 2 is influenced by the choice of the redox material, the temperature profile and the oxygen partial pressure in the HX. Of those quantities only the oxygen partial pressure can be influenced without affecting the reactors. To do so an interesting approach could be to introduce an oxygen sink in the HX. A second redox material could be oxidized with the oxygen released in the $\mathrm{HX}\left(\Delta \delta_{12}\right)$ and then be reduced at lower reduction temperatures than ceria, as described in detail by Brendelberger et al. [42, 43]. This way the oxygen partial pressure in the HX is decreased, which in turn increases $\delta_{4}\left(p_{O_{2}, H X}, T_{4}\right)$. Hence, the point at which $\delta_{4}=\delta_{o x}$ and $\eta_{\text {sys }}=0$ (see Figure 5) is shifted to higher $\eta_{H X}$.

The third mechanism could be mitigated by an inert gas in the HX atmosphere. Under vacuum conditions the oxygen is transported according to a pressure gradient within the HX with little resistance. In an HX filled with an Inert gas, the oxygen transport mechanism would be diffusion, which is potentially slower [43].

\section{CONCLUSION}

A two step-solar thermochemical redox cycle based on ceria with a solid-solid heat exchanger was investigated. Reactors and solid-solid heat exchanger were modeled in Python and the oxygen crossover in the heat exchanger was calculated. Two different pressure-lock setups were studied, of which one (setup 2) had a negative impact on the system efficiency and is therefore not suitable for the process. With setup 1 the following observations are made:

1. The system efficiency can be improved compared to a process without heat exchanger up to a factor of 2.1. Due to a strong recombination effect at high heat exchanger efficiencies this improvement is however limited and heat exchanger efficiencies of more than $50 \%$ can even have a negative effect on the system's performance.

2. At low heat exchanger efficiencies the model suggests that the recombination is reversed, i.e. oxygen is transferred from the reduced to the oxidized material stream, which has a positive effect on the system efficiency. A second law analysis did not generally disprove this finding. However, due to the limitations of the entropy balance the phenomenon of reversed recombination cannot be confirmed either.

The results suggest two different pathways to improve the system performance: The first option is to aim for high heat exchanger efficiencies, while preventing recombination. Limited reaction kinetics and technical countermeasures, such as removing oxygen from the heat exchanger or introduction of an inert gas to limit the gas phase transport might reduce the recombination effect. However, with respect to the abovementioned literature, reaching high solid-solid heat recovery rates seems technically very challenging and this path might not turn out to be realistic.

Our study reveals a second, maybe more viable option, which is to operate the system at lower heat exchanger efficiencies and to make use of the reversed recombination effect. This way the efficiency can still be more than doubled. However, the feasibility of reversed recombination needs more thorough investigation. This can be done with a second law analysis in a spatially resolved model and experiments on this phenomenon. Finally, experiments on the kinetics of the oxygen transfer are necessary to receive more accurate results.

\section{ACKNOWLEDGEMENTS}

We would like to acknowledge the internal financial support of DLR through the program "Competition of Visions" in the frame of the project MBR2. In addition, this work has received funding from the project HOTPORT which is co-funded in the Klimaschutzwettbewerb "EnergieSystemWandel.NRW" by the state of Northrhine-Westphalia, Germany, and the European EFRE fund (funding code EFRE-0801589). We gratefully thank Dr. Josua Vieten, Dr. Luke Venstrom and Dr. Silvan Siegrist for many fruitful discussions. 


\section{REFERENCES}

1. Fischer, F. and H. Tropsch, Über die Herstellung synthetischer Ölgemische (Synthol) durch Aufbau aus Kohlenoxyd und Wasserstoff. Brennst. Chem, 1923. 4: p. 276-285.

2. Marxer, D., et al., Solar thermochemical splitting of $\mathrm{CO}_{2}$ into separate streams of $\mathrm{CO}$ and $\mathrm{O}_{2}$ with high selectivity, stability, conversion, and efficiency. Energy \& Environmental Science, 2017. 10: p. 1142-1149.

3. Chueh, W.C. and S.M. Haile, A thermochemical study of ceria: exploiting an old material for new modes of energy conversion and $\mathrm{CO}_{2}$ mitigation. Philosophical Transactions of the Royal Society A: Mathematical, Physical and Engineering Sciences, 2010. 368(1923): p. 3269-3294.

4. Bulfin, B., et al., Analytical Model of $\mathrm{CeO} 2$ Oxidation and Reduction. The Journal of Physical Chemistry C, 2013. 117(46): p. 24129-24137.

5. Panlener, R.J., R.N. Blumenthal, and J.E. Garnier, $A$ thermodynamic study of nonstoichiometric cerium dioxide. Journal of Physics and Chemistry of Solids, 1975. 36(11): p. 1213-1222.

6. Mogensen, M., N.M. Sammes, and G.A. Tompsett, Physical, chemical and electrochemical properties of pure and doped ceria. Solid State Ionics, 2000. 129(1-4): p. 6394.

7. Warren, K.J., et al., Theoretical and Experimental Investigation of Solar Methane Reforming through the Nonstoichiometric Ceria Redox Cycle. Energy Technology, 2017. 5(11): p. 2138-2149.

8. Bulfin, B., et al., Oxidation and Reduction Reaction Kinetics of Mixed Cerium Zirconium Oxides. The Journal of Physical Chemistry C, 2016. 120(4): p. 2027-2035.

9. Chueh, W.C., et al., High-flux solar-driven thermochemical dissociation of $\mathrm{CO}_{2}$ and $\mathrm{H}_{2} \mathrm{O}$ using nonstoichiometric ceria. Science, 2010. 330: p. 1797-1801.

10. Abanades, S., et al., Investigation of reactive cerium-based oxides for $\mathrm{H}_{2}$ production by thermochemical two-step watersplitting. Journal of Materials Science, 2010. 45(15): p. 4163-4173.

11. Brendelberger, S., et al., Counter flow sweep gas demand for the ceria redox cycle. Solar Energy, 2015. 122: p. 10111022.

12. Chueh, W.C., et al., High-Flux Solar-Driven Thermochemical Dissociation of $\mathrm{CO} 2$ and $\mathrm{H} 2 \mathrm{O}$ Using Nonstoichiometric Ceria. Science, 2010. 330(6012): p. 1797-1801.

13. Venstrom, L.J., et al., Efficient Splitting of $\mathrm{CO}_{2}$ in an Isothermal Redox Cycle Based on Ceria. Energy Fuels, 2014. 28: p. 2732-2742.

14. Lapp, J., J. Davidson, and W. Lipiński, Efficiency of twostep solar thermochemical non-stoichiometric redox cycles with heat recovery. Energy, 2012. 37(1): p. 591-600.

15. Brendelberger, S., et al., Performance Assessment of a Heat Recovery System for Monolithic Receiver-Reactors. Journal of Solar Energy Engineering, 2019. 141(2): p. 021008021008-9.

16. Muhich, C.L., et al., Comparing the solar-to-fuel energy conversion efficiency of ceria and perovskite based thermochemical redox cycles for splitting $\mathrm{H} 2 \mathrm{O}$ and $\mathrm{CO} 2$. International Journal of Hydrogen Energy, 2018. 43(41): p. 18814-18831.

17. Diver, R.B., et al., Solar Thermochemical Water-Splitting Ferrite-Cycle Heat Engines. Journal of Solar Energy Engineering, 2008. 130(4): p. 41001-41008.

18. Miller, J.E., et al., Development and assessment of solarthermal activated fuel production: Phase 1 Summary, in Sandia Report. 2012, Sandia National Laboratories: Albuquerque, New Mexico.

19. Mayer, L.J. and J.L. Darryl, Thermal Recuperation Modeling of a Solar Thermochemical Reactor, in Proceedings of the ASME 2011 5th International Conference on Energy Sustainability. 2011. p. 729-736.

20. Lapp, J., J.H. Davidson, and W. Lipiński, Heat Transfer Analysis of a Solid-Solid Heat Recuperation System for Solar-Driven Nonstoichiometric Redox Cycles. Journal of Solar Energy Engineering, 2013. 135(3): p. 031004.

21. Richter, S., et al. Demonstration Reactor System for the Indirect Solar-Thermochemical Reduction of Redox Particles: The Particle Mix Reactor. in ASME 2019 13th International Conference on Energy Sustainability collocated with the ASME 2019 Heat Transfer Summer Conference. 2019.

22. Felinks, J., et al., Heat recovery concept for thermochemical processes using a solid heat transfer medium. Applied Thermal Engineering, 2014. 73(1): p. 1004-1011.

23. Ermanoski, I., N.P. Siegel, and E.B. Stechel, A New Reactor Concept for Efficient Solar-Thermochemical Fuel Production. Journal of Solar Energy Engineering, 2013. 135(3): p. 031002.

24. Ermanoski, I. and A. Orozco, C2R2: Compact Compound Recirculator/Recuperator for Renewable Energy and Energy Efficient Thermochemical Processing, in SAND2015-7320, SANDIA, Editor. 2015, SAND20157320.

25. Falter, C.P. and R. Pitz-Paal, $A$ generic solarthermochemical reactor model with internal heat diffusion for counter-flow solid heat exchange. Solar Energy, 2017. 144: p. 569-579.

26. Falter, C., A. Sizmann, and R. Pitz-Paal. Perspectives of advanced thermal management in solar thermochemical syngas production using a counter-flow solid-solid heat exchanger. in AIP Conference Proceedings. 2017. AIP Publishing.

27. Falter, C.P., A. Sizmann, and R. Pitz-Paal, Modular reactor model for the solar thermochemical production of syngas incorporating counter-flow solid heat exchange. Solar Energy, 2015. 122: p. 1296-1308.

28. Siegrist, S., et al., Moving Brick Receiver-Reactor: A Solar Thermochemical Reactor and Process Design With a SolidSolid Heat Exchanger and On-Demand Production of 
Hydrogen and/or Carbon Monoxide. Journal of Solar Energy Engineering, 2019. 141(2).

29. The Python Language Reference. [cited 2019 12-13-2019]; Available

from: https://docs.python.org/3.6/reference/index.html.

30. Bale, C.W., et al., FactSage thermochemical software and databases, 2010-2016. Calphad, 2016. 54: p. 35-53.

31. Touloukian, Y. and E. Buyco, Thermophysical properties of matter-The TPRC data series. Volume 5. Specific heatnonmetallic solids. 1970, Thermophysical Properties Research Center.

32. Bulfin, B., et al., Thermodynamics of $\mathrm{CeO} 2$ Thermochemical Fuel Production. Energy \& Fuels, 2015. 29(2): p. 1001-1009.

33. Brendelberger, S., et al., Performance analysis of operational strategies for monolithic receiver-reactor arrays in solar thermochemical hydrogen production plants. International J. Hydrogen Energy, submitted 2019.

34. Xu, C., et al., Energy and exergy analysis of solar power tower plants. Applied Thermal Engineering, 2011. 31(17): p. 3904-3913.

35. Dubbel - Taschenbuch für den Maschinenbau, 23. Auflage (Hrsg.: Grote, K.-H.; Feldhusen, J.). Berlin/Heidelberg/New York/London/Paris/Tokyo/Hong Kong. 2012, Barcelona: Springer-Verlag.

36. Borgnakke, C. and R.E. Sonntag, Fundamentals of Thermodynamics. 7th ed. 2009: John Wiley \& Sons, Inc.

37. Bulfin, B., et al., Statistical thermodynamics of nonstoichiometric ceria and ceria zirconia solid solutions. Physical Chemistry Chemical Physics, 2016. 18(33): p. 23147-23154.

38. Chase, M.W., S. National Institute of, and Technology, NIST-JANAF thermochemical tables. 1998, [Washington, D.C.]; Woodbury, N.Y.: American Chemical Society ; American Institute of Physics for the National Institute of Standards and Technology.

39. Barin, I., Thermochemical Data of Pure Substances. 3. ed ed. 1995, Weinheim: Wiley-VCH.

40. Marxer, D., et al., Solar thermochemical splitting of CO2 into separate streams of $\mathrm{CO}$ and $\mathrm{O} 2$ with high selectivity, stability, conversion, and efficiency. Energy \& Environmental Science, 2017. 10(5): p. 1142-1149.

41. Li, S., et al., Thermodynamic Analyses of Fuel Production via Solar-Driven Non-stoichiometric Metal Oxide Redox Cycling. Part 1. Revisiting Flow and Equilibrium Assumptions. Energy \& Fuels, 2018. 32(10): p. 1083810847.

42. Brendelberger, S., et al., Vacuum pumping options for application in solar thermochemical redox cyclesAssessment of mechanical-, jet-and thermochemical pumping systems. Solar Energy, 2017. 141: p. 91-102.

43. Brendelberger, S., et al., Demonstration of thermochemical oxygen pumping for atmosphere control in reduction reactions. Solar Energy, 2018. 170: p. 273-279. 